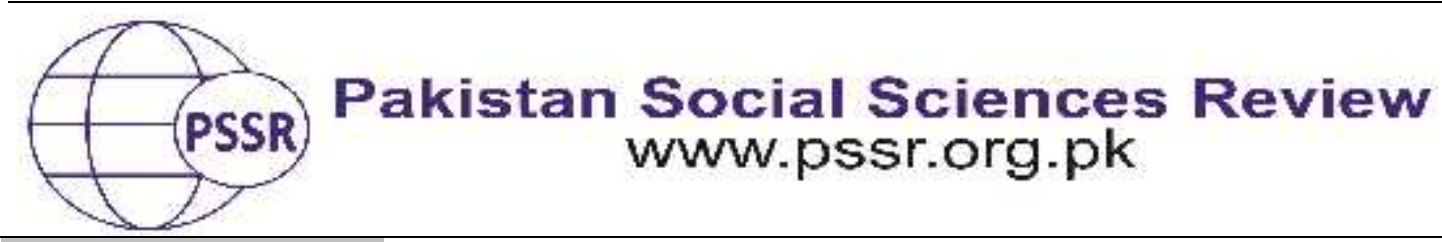

RESEARCH PAPER

\title{
A Comparative Study of Personality Dynamics between Boarders and Day Scholars at Higher Level
}

\author{
Kiran Shehzadi ${ }^{1}$ Umm-e-Farwaํㄹ Farzana Yousaf ${ }^{3}$
}

1. Lecturer, Department of Education, University of Education Lahore, Punjab, Pakistan

2. Lecturer, Department of Education, University of Education Lahore, Punjab, Pakistan

3. Lecturer, Department of Education, University of Education Lahore, Punjab, Pakistan

\section{PAPER INFO}

Received:

November 03, 2019

Accepted:

December 25, 2019

Online:

December 31, 2019

Keywords:

Day Scholars,

Higher Level,

Hosteller,

Personality

Development Traits,

Students

*Corresponding

Author

kiran.shahzadi@ ue.edu.pk

\section{ABSTRACT}

Personality is a vibrant organization, inside the individual, of psychophysical structures that produce a person's distinguishing patterns of behavior, judgments, and feelings. The major objective of the present study was to determine the personality dynamics of boarder students and day scholars. The sample of the study is comprised of 150 male and 150 female students taken from public sector universities of Lahore district. NEO personality inventory developed by McCrae and Costa, (1995) was used to collect the data. Inferential statistics were applied to compare the personality dynamics of hosteller and day scholars based on their gender and discipline of study. Results indicated that hostellers are less sociable, talkative, gregarious, assertive, active, ambitious and expressive as compared to day scholars. Male students showed significant personality dynamics than female students. By comparing disciplines, students enrolled in humanities group revealed more personality development traits than science students. This study recommends suggestions to the higher education institutes to provide mentoring programs for the boarders to strengthen their personality development traits.

\section{Introduction}

Personality is the combination of numerous characteristics which are reliable and permanent. Personality is what a person is that is expressed through communication. The two important aspects of personality include thinking and behaving, while thinking is associated with the emotions and feelings. Thinking processes are affected by the life experiences of an individual (Iftikhar \& Ajmal, 2015) having major impact on a person's personality. The term personality is derived from the Latin word 'Persona.' At first time, this term was used for the mask worn by the artists Roman and Greek in primordial times, to specify to the audiences whether they played the villain's or the hero's role in a drama. Therefore, the mask 
gave the artist his distinguishing features. Personality could also be defined as the divergent thought patterns, feelings, social adaptations, and activities frequently showed overtime that strongly affects one's beliefs, self-concept, values, and behaviors (Boyle, Matthews \& Saklofske, 2008).

Personality behaviors are usually described as dimensions of people in terms of comparatively stable aspects of behavior, thinking, and emotions (e.g., McCrae \& Costa, 2003). Big Five personality traits are the five main areas of personality that are employed to express personality and are called Five Factor Model (FFM) (Costa and McCrae, 1992). The first one among the Big Five factors is "openness to experience" which is concerned with intellectuality, curiosity and inspiration. Another element is "conscientiousness" that compacts with the structures of organization, dependability and goal orientation.

Human dynamics such as intellectual qualities, sympathetic, skillful or talent depend on psychological and bodily aspects of an organism (Seagal, 2002; Ritter, 2008). Cherry (2011), views that a person's behavior is not pre-decided, slightly it is formed on his inclinations. Education also plays a significant role in terms of providing experiences and learning opportunities to learn the ways of social adjustment by shaping up their attitudes and behavior (Jeff \& smith, 1999).

Two types of education systems are prevailed in Pakistani education including religious education given in Madrassahs and second being formal starting from British royal law and sustained after country's freedom (Memon, 2007). Though, education is very important both for male and female now a day. There are two types of students coming to the institutions of higher education, they are: (1) hosteller, (2) day scholars.

Boarding is classified as a place where students live temporarily for the purpose of gaining education. However, hostel is not perceived as a place but also an opportunity to learn a set of values under the supervision of adults in charge of getting compliance for the set rules. During their stay they tend to grasp the understanding of the curriculum through questioning with their peers that also contribute to their character building as well. According to Mishra (1994), they also learn how to improve their personal capabilities and learn to live freely (Mishra, 1994). Boarding house also provide opportunities to upbringing personality and help in social adjustment, students away from home feel hostel like a home and live like a family with each other's' support and cooperation (Terry,1994).

This boarding experience provides a sense of team work and spirit to cooperate with each other and develops the sentiment of family relationship. This inspires them to keep up in a comprehensive way later on in the practical life (Moffat, 2011).Besides this, day scholars live with their parents and feel more secure and comfortable in terms of their physical and psychological needs as compared to a hostel student. Domestic care has a great influence on personality development (Little, Kohm \& Thompson, 2005). Students who mostly live with their parents 
receive more residential care and supportive environment on personality development as well as have more control on their emotions and feel confident as compared to boarders.

With reference to dimension of character fuse mix boarders revealed less character direction as hosteller when compared with day researcher understudy counted high on these dimensions (response, difficult dread organization, defense, hesitation, corruption). The character of hostlers and non-hostler was discovered establishing that there was perilous difference between both gatherings on real elements of the character (Kumar et al., 2009). Day scholars are proved to be more helpful (physically and deeply) and predominantly have favored self-idea over visitors (Dambuzo, 2009).

The current study aims to determine the personality dynamics of students studying in public sector universities. This study further investigates the personality dynamics between day scholars and hosteller of public sector universities of Lahore district. Thus, this study examines the personality traits of students who live with their parents and those who stay at boarding house and how this impact on their personality and on their study career.

\section{Hypothesis}

The study follows the following hypotheses:

H01. There will be a significant difference between students living in hostels and day scholars on personality dynamics Inventory.

H02. There will be a significant difference between students living in hostels and day scholars on personality dynamics Inventory based on their gender.

H03. There will be a significant difference between students living in hostels and day scholars on personality dynamics Inventory based on their subject of study (science and Arts).

\section{Methods and Materials}

The study adopted descriptive survey design to carry out this research work.

\section{Sample and Sampling Technique}

The study comprised of 300 boarders and day scholars including 150 male and 150 female students from public universities selected through random sampling. The following table is describing the summary of demographic variables. 
Table 1

Demographic Characteristics of the Sample

\begin{tabular}{ccc}
\hline Variable & N & $\%$ \\
\hline Students & 150 & 50 \\
Boarders & 150 & 50 \\
Day scholars' & 150 & 50 \\
Gender & 150 & 50 \\
Male & & \\
Female & 150 & 50 \\
Department & 150 & 50 \\
Science & & \\
Humanities & & \\
\hline
\end{tabular}

\section{Measures}

NEO personality inventory (NEO-PI, McCrae and Costa, (1995) was used to collect data. NEO-PI is a self-report inventory comprising of 40 statements. The adapted tool retained the anticipated factor construction and presented somewhat better internal consistency, cross-observer agreement, and readability. The NEO-PI3 seems to be valuable in high school and college samples and may have wider applicability to adults as well.

These forty items were divided into five aspects namely openness to experience, conscientiousness, extraversion, agreeableness, and neuroticism. Openness to experiences, conscientiousness, Neuroticism consists of 8 items. Extraversion consists of 9 items. Agreeableness consists of 7items. The questionnaire was based on Liker type agreement scale in which student were asked to respond the statement by choosing one of the following five keys. Cronbach Alpha reliability for the personality inventory in this study was 0.73 .

\section{Data Collection}

Formal permission was taken from public sector universities of Lahore district, after explaining the purpose of the study. Participants were recruited through their head of departments for day scholar and hostel in-charge to approach students from hostel for data collection. Respondents were briefed regarding how to fill the survey while ensuring their participation through consent forms that were attached to the survey forms. The participants were requested to choose the option found close to their agreement corresponding to the statement. They were ensured that their responses will be kept confidential and will not be shared with any organization. It took 15-20 minutes to complete the questionnaire. The respondents were also informed to share the result of the study upon their request. 


\section{Data analysis}

The data were analyzed with the help of SPSS, descriptive and inferential statistics in order to answer the research question of the study. The following tables present the analysis of the data on the dependent variables.

\section{Results and Discussion}

Table 2

t-test for Comparison of Personality Traits of Boarders and Day scholars

\begin{tabular}{cccccccc}
\hline $\begin{array}{c}\text { Personality } \\
\text { dynamics }\end{array}$ & \multicolumn{7}{c}{ Boarders Day scholars } \\
& $\mathrm{M}$ & $\mathrm{SD}$ & $\begin{array}{c}(\mathrm{n}=150) \\
\mathrm{M}\end{array}$ & $\mathrm{SD}$ & $\mathrm{t}=150)$ & $\mathrm{p}$ & \\
\hline Extraversion & 30.13 & 7.71 & 33.88 & 4.07 & -4.29 & $.000^{* * *}$ \\
\hline Neuroticism & 25.66 & 7.11 & 28.33 & 6.63 & -2.74 & $.007^{* *}$ \\
\hline $\begin{array}{c}\text { Openness to } \\
\text { experience }\end{array}$ & 26.54 & 7.02 & 29.01 & 3.97 & -3.06 & $.003^{* *}$ \\
\hline Agreeableness & 22.67 & 5.44 & 24.78 & 4.00 & -3.12 & $.002^{* *}$ \\
\hline conscientiousness & 26.47 & 8.58 & 28.21 & 4.40 & -1.80 & .073 \\
\hline $\mathrm{df}=198,{ }^{* * *} \mathrm{p}<.000,{ }^{*} \mathrm{p}<.05,{ }^{* *} \mathrm{p}<.001$ & & & &
\end{tabular}

Table 2 shows the significant differences between boarders and day scholars' personality dimensions. It is evident in the table that significant differences are present between boarding and day scholars' personality dimensions including extraversion, neuroticism, openness to experience, and agreeableness. Only for the dimension conscientiousness insignificant difference was observed. The significant differences revealed through t-test show the results in favor of day scholars' as the mean values obtained are higher for the day scholars as compared to boarding students.

Table3

t-test for Comparison of Personality Traits of Male and Female Students' Personality Dynamic Traits

\begin{tabular}{|c|c|c|c|c|c|c|}
\hline \multirow{3}{*}{$\begin{array}{c}\text { Personality } \\
\text { dynamics }\end{array}$} & \multicolumn{4}{|c|}{ Male female } & \multirow[b]{3}{*}{$t$} & \multirow[b]{3}{*}{$p$} \\
\hline & \multicolumn{2}{|c|}{$(n=150)$} & \multicolumn{2}{|c|}{$(n=150)$} & & \\
\hline & & SD & $M$ & SD & & \\
\hline Extraversion & 33.14 & 4.81 & 30.87 & 7.58 & 2.52 & $.012^{*}$ \\
\hline Neuroticism & 27.40 & 5.45 & 26.59 & 8.25 & .819 & .414 \\
\hline $\begin{array}{l}\text { Openness to } \\
\text { experience }\end{array}$ & 28.97 & 4.81 & 26.58 & 6.48 & 2.95 & $.003^{* *}$ \\
\hline Agreeableness & 24.95 & 4.34 & 22.50 & 5.10 & 3.65 & $.000^{* * *}$ \\
\hline Conscientiousness & 29.23 & 6.38 & 25.45 & 6.82 & 4.04 & $.000^{* * *}$ \\
\hline
\end{tabular}

Table 3 shows significant differences based on gender of the students. The study revealed that male is higher in their perception towards all of the personality dimensions except for the neuroticism for which non-significant differences were 
observed. Results showed that on average, male students held more positive tendency towards extraversion, openness to experience, agreeableness and conscientiousness, the mean values obtained for male students are higher as compared to their female counterparts. The results are logical as it confirms the notion specified for the dominant character of male in the society. This dominance helps male to exercise all these positive aspects of personality dimensions. Along with this dominance male members are responsible for most of the financial as well as outdoor responsibilities that become the base of personality development in a more positive way.

Table 4

t-test for Comparison of Students' Personality Dynamics of Science and Humanities Departments

\begin{tabular}{ccccccc}
\hline Personality & \multicolumn{7}{c}{ Science Humanities } \\
dynamics & $\mathrm{M}$ & $\mathrm{SD}$ & $\mathrm{M}$ & $\mathrm{(n}=150)$ & & \\
Extraversion & 30.59 & 7.91 & 33.42 & 4.07 & -3.17 & $.002^{* *}$ \\
Neuroticism & 25.30 & 6.98 & 28.69 & 6.60 & -3.52 & $.001^{* *}$ \\
Openness to & 26.78 & 6.83 & 28.77 & 4.41 & -2.44 & $.015^{*}$ \\
experience & & & & & & \\
Agreeableness & 22.49 & 5.51 & 24.96 & 3.80 & -3.68 & $.000^{* * *}$ \\
Conscientiousness & 25.60 & 7.36 & 29.08 & 5.84 & -3.70 & $.000^{* * *}$ \\
\hline
\end{tabular}

$\mathrm{df}=198,{ }^{* * *} \mathrm{p}<.000,{ }^{*} \mathrm{p}<.05,{ }^{* *} \mathrm{p}<.001$

Table 4 shows the significant differences found between students' personality dimension of science and humanities departments. It is quite clear in the results that students of humanities group are higher in their responses to personality dimensions. Significant differences are revealed for all of the dimensions of personality. The results might be due to the nature of academic stress involved for humanities group that is supposed to be less rigid, and requires less effort as compared to students studying science subjects. The data discovered that students of humanities group are more extroverts. Students of humanities group are more considerate and cooperative.

\section{Discussion}

The study under investigation aimed to compare personality dynamics of students living in hostels and those being day scholars. Primarily it was hypothesized that day scholars held more personality dynamics than the hostler. Based on results of present study, the hypothesis claiming significant difference between boarding and day scholars is supported and showed that day scholars held more positive personality dynamics as compared to boarding students.

The results confirmed that place of residence does affect the personality dynamics of students. It is observed that as compared to day scholar students, hosteller showed substantial difference on major dimensions of personality such as 
neuroticism, openness, agreeableness, conscientiousness and extraversion. This finding is aligned to the results found by Kumar, Reader and Arun (2009),affirming that children sent to boarding school might have lack of emotional expression(Kumar, Reader \&Arun, 2009).

Similar findings can be found form the research study conducted by Parveen and Kazmi (2011) that showed that non-boarders students were found to be more open to interact. However, they found neuroticism as being higher in boarders. The reason behind of this finding might be due to the fact of living away from home causing homesickness that lead to depression or anxiety disorders (Nayar, 2018; Khurshid, Tanveer \& Qasmi, 2012).Boarding students were also found having less adjustment in health, emotions and domestic areas (Marwaha, 2015; Terry, 1998). Comparable views about the aversive effect of boarding house on personality dynamics (Burt, 1993; Raju, 2009).Being part of a home and family helps in improving personality (Little, Kohm\& Thomson, 2005).

Boarders are found with lack of emotional expression which then can transform into behavioral issues. This is quite obvious in the results revealed by the present study that students residing in boarding houses showed less friendliness. Day scholars were evidenced to be healthier (physically and emotionally) and especially possess better self-concept than boarders (Dambuzo, 2009). The results of present study confirm the findings obtained by Parveen and Kazmi (2011) reporting the negative effect of boarding on children's' personality. They found children of boarding schools were as fewer extroverts as compared to day scholar students. Similar results were described by Togonoli (2003) for boarding students showing lower scores for ego and self-esteem etc.

Second major aim of the study was to explore and compare the personality dynamics of male and female students. The results found male students as being higher in their personality development compared to female counterparts. Nature of the results could be due to the differences in male and female characters in the society. These differences are created by the various institutions in the society such as media, family and peer etc. The expectations of religion, and society also develop gender roles (Rahmani \& Lavasani, 2012).

Studies found that male are found to be more cooperative, do not hesitate to engage in group competitions (Benenson, 2013; Geary, Hoard, Vigil \&Numtee., 2003). Male are happened to be more cooperative with other male partners as compared to female-female pairs (Balliet et al., 2011). The results are quite logical considering the Pakistani society where male members from an early age are taught to perform most of the domestic activities requiring outdoor interaction (Daily life and social customs, 2019, para 1). It helps in having more socialization with the environment and people. Therefore, they tend to have more opportunities to interact and manage various styles of personality. This creates sense of compromise, cooperation, tolerance, and confidence as well. Consequently, majority of the male tend to have more positive, confident and social brought up. The opinion of society is conservative regarding female members of the society (Ali, Krantz, Gul, Asad, 
Johnson \&Mogren, 2011). They are supposed to stay at home and perform domestic indoor activities. However, Pakistan being developing country encourages to let female go to academic institutions, study and perform various jobs in the society. Although this is quite helpful in enhancing the image of female in the society but it is still in infancy stage(Nasir, 2012). Thus, female still get less opportunities of socialization as major burden are on male members who share the burden of family by himself. That's why we found male students as having more profound dynamics of positive personality.

Another finding of the study was to examine the personality dynamics of students having humanities and science study background. The results found that students with humanities group are better in terms of personality dimensions compared to students with science background. Students of humanities group are more extroverts, considerate, agreeable and social. It could be due to the fact that classroom of humanities group are more democratic, have space for the sharing of ideas, development of various point of views through interactive mode of teaching and learning. The class environment is more social as compared to the situation in science classrooms. Outdoor activities of students from humanities group also happened to be more free, leisure time activities, and travel opportunities, more chances to engage in group projects etc. such activities occur less in classrooms of students studying science. They demonstrate work through labs, carrying out experiments, so this study confirm that the nature of the discipline help in developing an extrovert, lonely and quite personality.

\section{Conclusions}

On the base of attained results, it is decided that place of residence variable has a major effect on personality dynamics. Hostellers are a diverse group, who has exclusive needs and problems. They have specific physical, social and emotional characteristics, developed as a result of living away from their home, learning to accomplish their own affairs and regulate to new condition of living environment without family support or experience to guide them. These hostellers, who live independently, are subject to less parental control that can inhibit unhealthy behavior. Hosteller students revealed less friendly, talkative, gregarious, selfconfident, energetic, determined and communicative as compared to day scholars' students. Extraversion was the highest personality traits and amicability was the lowest personality traits in both hosteller and day scholars' students. Neuroticism, openness to experience, scrupulousness fell between extraversion and amicability. However, and this study provides implications for the future research to target a big sample of students from hostel and day scholar to generalize the results of the study as it was limited on a smaller sample. This study was based on quantitative research design and needs to done through qualitative research to further explore the factors that are accountable in terms of personality development traits. 


\section{References}

Ali, T. S., Krantz, G., Gul, R., Asad, N., Johansson, E., \&Mogren, I. (2011). Gender roles and their influence on life prospects for women in urban Karachi, Pakistan: A qualitative study. Global Health Action, 4(1), 7448.

Bahadar, N. M. W., Jadoon, S., and Jadoon, S. (2014). A comparative analysis of the behaviors and performance of day scholar and boarder students at secondary schoollevel. Am Educ Res J. 2014, 2:600-602. 10.12691/education-2-8-7

Balliet, D., Mulder, L. B., \& Van Lange, P. A. (2011). Reward, punishment, and cooperation:a meta-analysis. Psychological Bulletin, 137(4), 594.

Benenson, J. F. (2013). The development of human female competition: Allies and adversaries. Philosophical Transactions of the Royal Society B: Biological Sciences, 368 (1631), 20130079.

Boyle, G. J., Matthews, G., \& Saklofske, D. H. (2008). Personality measurement and testing: An overview. The SAGE handbook of personality theory and assessment, 2, 1 26.

Cherry, K. (2011). About.com Guide to Psychology. Retrieved from http://psychology.about.com/ od/psychology101/u/psychology-theories.htm

Dambudzo, I. I. (2009). The relationship between learner self-concept and achievement in secondary schools in Zimbabwe(Doctoral dissertation).

Encyclopedia Britanica (2019). Daily life and social customs.Https:// www.britannica.com/place/Pakistan/Daily-life-and-socialcustoms

Geary, D. C., Byrd-Craven, J., Hoard, M. K., Vigil, J., \&Numtee, C. (2003). Evolution and development of boys' social behavior. Developmental Review, 23(4), 444-470.

Iftikhar, A., \& Ajmal, A. (2015). A qualitative study investigating the impact of hostel life. Int J Emergency Mental Health Human Resilience, 17(2), 511-5.

Jackson, L. M., Pancer, S. M., Pratt, M. W., \&Hunsberger, B. E. (2000). Great expectations: The relation between expectancies and adjustment during the transition to university. Journal of Applied Social Psychology, 30(10), 2100-2125.

Jeff, T., \& Smith, M. K.(1999). What is education? http://www.infed.org/found ati ons / f-educ.htm.

Khurshid, F., Tanveer, A., and Qasmi, F. N (2012). Relationship between study habits and academic achievement among hostel living and day scholars' university students. British Journal of Humanities and Social Sciences. 3, 34-42. 
Kumar, M. M., \& Reader, Arun, K. (2009). Comparative study of personality pattern of hostlers and no hostlers at senior secondary school students. The Journal of Progressive Education, 2(2).

Little, M., Kohm, A., \& Thompson, R. (2005). The impact of residential placement on child development: Research and policy implications. International Journal of Social Welfare, 14(3), 200-209.

Marwaha, S. (2015). Analysis and comparison of adjustment level of college day scholars and hostellers in terms of their home, health, social, emotional and educational adjustment. Hum Mov Sci. 1, 1-8.

McCrae, R. R., \& Costa, P. T. (2003). Personality in adulthood: A five-factor theory perspective. Guilford Press.

Memon, G.R. (2007). Education in Pakistan: The Key Issues, Problem and the New Challenges. Journal of Management and Social Sciences, 3(1), 47-55.

Moffat. (2011). Overall Personality Development of the Students Is Primed by the Boarding School UK. http://www.bukisa.com/articles /434153_overall-personalitydevelopment-of-thestudents-is-primed-by-the-boarding-school-uk

Nasir, S. (2012). Women empowerment. https://www.pakistantoday.com.pk/2012/03/07/women-empowerment-3/

Nayar, N. (2018). Depression, anxiety, perceived loneliness among school-going adolescents. A comparative study between hostellers and day boarders. J Med SciClin Res., 6,344-348.

Paul T. Costa Jr. \& Robert R. McCrae (1995). Domains and facets: Hierarchical personality assessment using the revised NEO personality inventory. Journal of Personality Assessment, 64(1), 21-50.

Perveen, S.Kazmi, S. (2011). Personality dynamics of boarders and day scholars who belong to Madrassah and public school. ARInt. 2011, 1:157-172.

Poropat, A. E. (2009). A meta-analysis of the five-factor model of personality and academic performance. Psychol Bull. 135, 322-338. 10.1037/a0014996

Rahmani, S., \&Lavasani, M. G. (2012). Gender differences in five factor model of personality and sensation seeking. Procedia-Social and Behavioral Sciences, 46, 2906-2911.

Raju, T. (2009). Personality and Adjustment of University Hostel students. http:/ / books.google.com.pk/books?hl=en\&lr=\&id=X7I4RF9d9nAC\&oi=fnd\&pg $=$ PA1\&dq=hostel ++ and ++ student + personality $+\& o t s=$ GoOFfz88rA\&sig=wzNve 
viIVp8biUkFr_J_82dxg3w\#v=onepage\&q=hostel $\% 20 \% 20$ and $\% 20 \% 20$ student $\% 20$ personality\&f=false.ISBN.978-81-8356 -424-3.

Ritter, D. (2008). A Brief Overview of Human Dynamics. Life and Spiritual Coaching, July. http:/ / dritter55.wordpress.com/2008/ 07/09/a-brief-review-of-humandynamics/

Seagal, S. (2002). The Human Dynamics Body of Knowledge and its Implications for Education: A Brief Account. New Horizons for Learning, http://www.marthalakecov.org/ building/strategie s/styles/horne.html.

Terry, D. J. (1994). Determinants of coping: The role of stable and situational factors. Journal of Personality and Social Psychology, 66(5), 895.

Tognoli, J. (2003).Leaving Home Homesickness, Place Attachment, and Transition among Residential College Students. Journal of College Student Psychotherapy, 18(1), 35-48.DOI: 10.1300/J035v18n01_04 